\title{
Electrokinetic Techniques for the Determination of Hydraulic Conductivity
}

\author{
Laurence Jouniaux \\ Institut de Physique du Globe de Strasbourg, \\ Université de Strasbourg, Strasbourg
}

France

\section{Introduction}

In a porous medium the fluid flux and the electric current density are coupled, so that the streaming potentials are generated by fluids moving through porous media and fractures. These electrokinetic phenomena are induced by the relative motion between the fluid and the rock because of the presence of ions within water. Both steady-state and transient fluid flow can induce electrokinetics phenomena. It has been proposed to use this electrokinetic coupling to detect preferential flow paths, to detect faults and contrast in permeabilities within the crust, and to deduce hydraulic conductivity. This chapter proposes a comprehensive review of the electrokinetic coupling in rocks and sediments and a comprehensive review of the different approaches to deduce hydraulic properties in various contexts.

Electrical methods are sensitive to the fluid content because of the relative high conductivity of water compared to the one of the rock matrix. The electrical resistivity can be related to the permeability and to the deformation, in full-saturated or in partially-saturated conditions (Doussan \& Ruy, 2009; Henry et al., 2003; Jouniaux et al., 1994; 2006). The electrokinetic phenomena are induced by the relative motion between the fluid and the rock matrix. In a porous medium the electric current density, linked to the ions within the fluid, is coupled to the fluid flow (Overbeek, 1952) so that the streaming potentials are generated by fluids moving through porous media (Jouniaux et al., 2009). The classical interpretation of the self-potential (SP) observations is that they originate from electrokinetic effect as water flows through aquifer or fractures. Therefore some formula have been proposed to predict the permeability of porous medium or fault using the electrokinetic properties. The SP method consists in measuring the natural electric field on the Earth's surface. Usually the electric field is measured by a high-input impedance multimeter, using impolarizable electrodes (Petiau, 2000; Petiau \& Dupis, 1980) and its interpretation needs filtering techniques (Moreau et al., 1996). Moreover, for long-term observations the monitoring of the magnetic field is also needed for a good interpretation (Perrier et al., 1997). Some studies have proposed to use SP observations to infer water-table variations, to estimate hydraulic properties (Glover \& Walker, 2009), and to deduce where to make a borehole for water-catchment. These studies involve surface or borehole measurements (Aubert \& Atangana, 1996; Fagerlund \& Heison, 2003; Finizola et al., 2003; Perrier et al., 1998; Pinettes et al., 2002), some of them have monitored self-potentials during hydraulic tests in boreholes (Darnet et al., 2006; Darnet \& Marquis, 2004; Ishido et al., 1983; Maineult et al., 2008). Direct models 
(Ishido \& Pritchett, 1999; Jouniaux et al., 1999; Sheffer \& Oldenburg, 2007) and inverse problems (El-kaliouby \& Al-Garni, 2009; Fernandez-Martinez et al., 2010; Gibert \& Pessel, 2001; Gibert \& Sailhac, 2008; Minsley et al., 2007; Naudet et al., 2008; Sailhac et al., 2004; Saracco et al., 2004) have been developed to locate the source of self-potential. Because of similarity between the electrical potential with pressure behavior, it has been proposed also to use SP measurements as an electrical flow-meter (Pezard et al., 2009). However, inferring a firm link between SP intensity and water flux is still difficult. Recent modeling has shown that SP observations could detect at distance the propagation of a water front in a reservoir (Saunders et al., 2008).

We distinguish 1) The steady-state and passive observations which consist in measuring the electrical self-potential (SP). 2) The transient and active observations which consist in measuring the electrical potential induced by the propagation of a seismic wave. These observations are called seismo-electric conversion. The reverse can also be observed: the detection of a seismic wave induced by injection of electrical current and is called electro-seismic conversion.

\section{Streaming potential coefficient in rocks and sediments}

\subsection{Theoretical background}

The fluid flow in porous media or in fractures can induce electrokinetic effect because of the presence of ions within the fluid which can induce electric currents when water flows. The general equation coupling the different flows is,

$$
\mathbf{J}_{i}=\sum_{j=1}^{N} \mathcal{L}_{i j} \mathbf{X}_{j}
$$

which links the forces $\mathbf{X}_{j}$ to the macroscopic fluxes $\mathbf{J}_{i}$, through transport coupling coefficients $\mathcal{L}_{i j}$ (Onsager, 1931).

When dealing with the coupling between the hydraulic flow and the electric flow, assuming a constant temperature, and no concentration gradients, the electric current density Je [A.m ${ }^{-2}$ ] and the flow of fluid $\mathbf{J}_{\mathbf{f}}\left[\mathrm{m} . \mathrm{s}^{-1}\right]$ can be written as the following coupled equation:

$$
\begin{aligned}
& \mathbf{J}_{\mathbf{e}}=-\sigma_{0} \nabla V-\mathcal{L}_{e k} \nabla P . \\
& \mathbf{J}_{\mathbf{f}}=-\mathcal{L}_{e k} \nabla V-\frac{k_{0}}{\eta_{f}} \nabla P .
\end{aligned}
$$

where $P$ is the pressure that drives the flow [Pa], $V$ is the electrical potential [V], $\sigma_{0}$ is the bulk electrical conductivity $\left[\mathrm{S} . \mathrm{m}^{-1}\right], k_{0}$ the bulk permeability $\left[\mathrm{m}^{2}\right], \eta_{f}$ the dynamic viscosity of the fluid [Pa.s], $\mathcal{L}_{e k}$ the electrokinetic coupling [ $\mathrm{A} \mathrm{Pa}^{-1} \mathrm{~m}^{-1}$ ]. Thus the first term in equation 2 is the Ohm's law and the second term in equation 3 is the Darcy's law. The coupling coefficients must satisfy the Onsager's reciprocal relation in the steady state: the coupling coefficient is therefore the same in equation 2 and equation 3 . This reciprocity has been verified on porous materials (Auriault \& Strzelecki, 1981; Miller, 1960) and on natural materials (Beddiar et al., 2002).

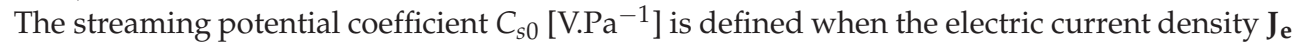
is zero, leading to 


$$
\frac{\Delta V}{\Delta P}=-\frac{\mathcal{L}_{e k}}{\sigma_{0}}=C_{s 0}
$$

This coefficient can be measured by applying a driving pore pressure $\Delta P$ to a porous medium and by detecting the induced electric potential difference $\Delta V$. The driving pore pressure induces a streaming current (second term in eq. 2) which is balanced by the conduction current (first term in eq.2) which leads to the electric potential difference $\Delta V$ that can be measured. We detail here what we know about this streaming potential coefficient (SPC) on sands and rocks because we will see that it can be used with the electro-osmosis coefficient to deduce the permeability. In the case of a unidirectional flow through a cylindrical saturated porous capillary, this coefficient can be expressed as (Jouniaux et al., 2000; Jouniaux \& Pozzi, 1995b):

$$
C_{s 0}=\frac{\epsilon_{f} \zeta}{\eta_{f} \sigma_{e f f}}
$$

with the fluid electrical permittivity $\epsilon_{f}\left[\mathrm{~F}_{\mathrm{m}}{ }^{-1}\right]$, the effective electrical conductivity $\sigma_{\text {eff }}$ [S.m $\left.{ }^{-1}\right]$ defined as $\sigma_{e f f}=F \sigma_{0}$ with $F$ the formation factor and $\sigma_{0}$ the rock conductivity which can include a surface conductivity. The potential $\zeta[\mathrm{V}]$ is the zeta potential described as the electrical potential inside the EDL at the slipping plane or shear plane (i.e., the potential within the double-layer at the zero-velocity surface). Minerals forming the rock develop an electric double-layer when in contact with an electrolyte, usually resulting from a negatively charged mineral surface. An electric field is created perpendicular to the surface of the mineral which attracts counterions (usually cations) and repulses anions in the vicinity of the pore matrix interface. The electric double layer (Fig. 1) is made up of the Stern layer, where cations are adsorbed on the surface, and the Gouy diffuse layer, where the number of counterions exceeds the number of anions (Adamson, 1976; Davis et al., 1978; Hunter, 1981). The streaming current is due to the motion of the diffuse layer induced by a fluid pressure difference along the interface. This streaming current is then balanced by the conduction current, leading to the streaming potential. When the surface conductivity can be neglected compared to the fluid conductivity $F \sigma_{0}=\sigma_{f}$ and the streaming coefficient is described by the well-known Helmholtz-Smoluchowski equation (Dukhin \& Derjaguin, 1974):

$$
C_{s 0}=\frac{\epsilon_{f} \zeta}{\eta_{f} \sigma_{f}}
$$

The assumptions are a laminar fluid flow and identical hydraulic and electric tortuosity. The influencing parameters on this streaming potential coefficient are therefore the dielectric constant of the fluid, the viscosity of the fluid, the fluid conductivity and the zeta potential, itself depending on rock, fluid composition, and $p H$ (Guichet et al., 2006; Ishido \& Mizutani, 1981; Jaafar et al., 2009; Jouniaux et al., 2000; Jouniaux \& Pozzi, 1995a; Lorne et al., 1999a; Vinogradov et al., 2010). There exists a $p H$ for which the zeta potential is zero: this is the isoelectric point and $p H$ is called $p H_{I E P}$ (Davis \& Kent, 1990; Sposito, 1989). At a given $p H$ the most influencing parameter is the fluid conductivity (Fig.2). When collecting data from literature on sands and sandstones we can propose that $C_{s 0}=-1.2 \times 10^{-8} \sigma_{f}^{-1}$ which leads to a zeta potential equal to $-17 \mathrm{mV}$ assuming eq. 6 and that zeta potential and dielectric constant do not depend on fluid conductivity. These assumptions are not exact, but the value of zeta is needed for numerous modellings which usually assume the dielectric constant not dependent on the fluid conductivity. Therefore an average value of $-17 \mathrm{mV}$ for such 
modellings is rather exact, at least for medium with no clay nor calcite. Another formula is often used (Pride \& Morgan, 1991) based on quartz minerals rather than on sands and sandstones, which may be less appropriate for field applications. When the medium is not fully saturated Perrier \& Morat (2000) suggested a model in which the streaming potential coefficient is dependent on a relative permeability model $k_{r}$.

$$
C\left(S_{w}\right)=C_{s 0} \frac{k_{r}}{S_{w}{ }^{n}}
$$

assuming that the relative electrical conductivity is equal to $S_{w}^{n}$. The parameter $n$ is the Archie saturation exponent (Archie, 1942). This exponent has been observed to be about 2 for consolidated rocks and in the range $1.3<n<2$ for coarse-texture sand (Guichet et al., 2003; Lesmes \& Friedman, 2005; Schön, 1996). Note that the use of Archie's law is valid in the absence of surface electrical conductivity. Recently Allègre et al. (2010) (and Allègre et al. (2011)) proposed original streaming potential measurements performed during a drainage experiment and measured the first continuous recordings of the streaming potential coefficient as a function of water saturation. These authors observed that the streaming potential coefficient exhibits two different behaviours as the water saturation decreases. Values of $C_{s 0}$ first increase for decreasing saturation in the range $0.55-0.8<S_{w}<1$, and then decrease from $S_{w}=0.55-0.8$ to residual water saturation. This behaviour was never reported before and still needs further interpretation. Jackson (2010) used a bundle capillary model to compute the streaming potential coefficent as a function of water-saturation. He showed that the behaviour of the SPC depends on the capillary size distribution, the wetting behaviour of the capillaries, and whether we invoke the thin or thick electrical double layer assumption. Depending upon the chosen value of the saturation exponent and the irreductible water-saturation, the relative SPC may increase at partial saturation, before decreasing to zero at the irreductible saturation. Up to now permeability predictions using electrokinetic techniques use theoretical developments in full saturated conditions.

Similarly the electro-osmosis coefficient is defined when the flow of fluid $\mathbf{J}_{\mathbf{f}}$ is zero, leading to

$$
\frac{\Delta P}{\Delta V}=-\frac{\mathcal{L}_{e k} \eta}{k_{0}}=C_{e 0}
$$

This coefficient can be measured by applying an electric potential difference $\Delta V$ and by detecting the induced electro-osmotic flow $\left[\mathrm{m} . \mathrm{s}^{-1}\right]$ corresponding to the first term of equation 3 , by controlling the hydraulic gradient, usually maintaining identical water heads. Assuming the Helmholtz-Smoluchowski equation (eq. 6) the electro-osmosis coefficient can be written as:

$$
C_{e 0}=\frac{\epsilon \zeta}{k_{0} F}
$$

and then depends also on $p H$ (Beddiar et al., 2005) through the zeta potential.

Since the permeability and the formation factor are not independent, but can be related by $k_{0}=C R^{2} / F$ (Paterson, 1983) with $C$ a geometrical constant usually in the range 0.3-0.5 and $R$ the hydraulic radius, the electro-osmosis coefficient can be written as:

$$
C_{e 0}=\frac{\epsilon \zeta}{C R^{2}}
$$


As we can see from this section, the streaming potential coefficient and the electro-osmosis coefficient are directly proportional to the zeta potential, which can not be directly measured and which is difficult to model at a rock-water interface. Therfore the zeta potential is usually deduced from streaming potential measurements. Moreover the streaming potential coefficient is inversely proportional to the fluid conductivity, whereas the electro-osmosis coefficient is inversely proportional to the hydraulic radius.

\subsection{Permeability prediction}

These electrokinetic properties have been used to predict the permeability. Li et al. (1995) defined an electrokinetic permeability $k_{e}$ by the following relation:

$$
k_{e}=\eta \sigma_{r} \frac{C_{s 0}}{C_{e 0}}
$$

with $\sigma_{r}$ the rock conductivity (measured when $\mathbf{J}_{\mathbf{f}}$ is zero).

These authors verified on 12 samples of sandstones, limestones and fused glass beads that the electrokinetic permeability $k_{e}$ successfully predicts the rock permeability $k_{r}$ (measured when $\mathrm{J}_{\mathbf{e}}$ is zero) over a range of about four decades from $10^{-15}$ to $10^{-11} \mathrm{~m}^{2}$. Pengra et al. (1999) verified also this relation on eight samples of sandstone and limestone, and four fused glass beads, in the permeability range $10^{-15}$ to $10^{-11} \mathrm{~m}^{2}$ (Fig. 3). This approach has been used to propose the permeability measurement (Wong, 1995) within boreholes (Fig. 4). The advantage was that we only needed to apply or to measure the pressure and the electric field.

A simplest way to measure the permeability in borehole, was performed using only the streaming potential coefficient (eq. 4). Although this coefficient does not depend directly on permeability, Hunt \& Worthington (2000) showed that the borehole streaming potential response could detect fractures and cracks. A pressure pulse is generated by a nylon block which displaces water as it moves upwards (Fig. 5). This mechanical system avoids spurious electrical noise induced by electro-mechanical systems. The electrode response is normalized to the peak pressure recorded by the hydrophone. The authors showed that the maximum electrical signal was clearly associated with the highest fracture density and the widest aperture $\left(\mathrm{few} \mathrm{cm}\right.$ ). The recorded amplitudes were in the range $4 \times 10^{-7}$ to $1.5 \times 10^{-6}$ $\mathrm{V} / \mathrm{Pa}$. It was proposed that the fluid flow in the cracks causing the streaming potential was predominantly caused by the seismic wave within the rock that distorts crack aperture as it passes, rather than by the source directly forcing fluid into cracks. In this case the permeability dependence of the streaming potential coefficient may be linked to the indirect effect of surface conductivity which may not be negligeable: the effective conductivity can decrease with increasing permeability, leading to an increase in the streaming potential coefficient (eq. 5) (Jouniaux \& Pozzi, 1995a).

Recently, Glover et al. (2006) proposed a new prediction for the permeability by comparing an electrical model derived from the effective medium theory to an electrical model for granular medium. These authors derived the RGPZ model defined as:

$$
k_{R G P Z}=\frac{d^{2} \phi^{3 m}}{4 a m^{2}}
$$

where $\phi$ is the porosity, $m$ the cementation exponent from the Archie's law, $a$ is a parameter thought to be equal to $8 / 3$ for samples composed of quasi-spherical grains, and $d$ is the relevant grain size. They showed that the relevant grain size is the geometric mean, which can be deduced from Mercury Injection Capillary Pressure (MICP). The relevant grain size 
can also be inferred from borehole NMR data, and then must be deduced from an empirical procedure relating grain size to the $T_{2}$ relaxation time. This new model was shown to match data over 348 samples over a $500 \mathrm{~m}$ thick sand-shale succession in the North Sea. Since the porosity can also be derived from NMR data, the advantage of this approach is to provide a log of permeability along the studied borehole, at the scale which is investigated by the NMR tool.

\section{Fault and hydraulic fracturing}

\subsection{Permeability prediction within fault}

It has also been proposed to deduce the permeability of the Nojima fault (Japan) using the self-potential observations in surface when water is injected into a well of $1800 \mathrm{~m}$ depth (Murakami et al., 2001). Water flow is induced at about $1600 \mathrm{~m}$ depth when crossing the fracture zone, and the change in voltage in the aquifer is conducted to the whole part of the well through the iron casing pipe (Fig. 6). Therefore the electrokinetic source occuring at depth can be detected at the surface. Self-potential variations of $10-35 \mathrm{mV}$ in response to water pressure of $35-38 \times 10^{5} \mathrm{~Pa}$ were observed. The magnitude of self-potential variations decreases with increasing distance from the injection well. An amplitude of $-20 \mathrm{mV}$ was detected near the well, about $-10 \mathrm{mV}$ at $40 \mathrm{~m}$, and within the noise at one hundred meters. The electrokinetic source is the dragging current expressed by the second term in eq. 2. Assuming the Helmholtz-Smoluchowski equation (eq. 6) and the Darcy's law (second term in eq. 3), and using the definition of the formation factor $F$, we can write the dragging current:

$$
\mathbf{J}_{\text {edragg }}=-\frac{\epsilon_{f} \zeta}{F k} \mathbf{J}_{\mathbf{f}}
$$

This dragging current is balanced by the conduction current (the first term in eq. 2). Assuming a line source model with $L$ the length of the casing pipe, the potential difference $\Delta \mathrm{V}$ between two electrodes at the surface is related to the total conduction current $I_{\text {cond-tot }}[\mathrm{A}]$ by (Murakami et al., 2001):

$$
\Delta V=\frac{I_{\text {cond }- \text { tot }}}{2 \pi \sigma_{r} L} \log (a / b)
$$

where $a$ and $b$ are the distances from the borehole to the electrodes. Then the permeability of the fault is deduced by:

$$
k_{\text {fault }}=-\frac{\epsilon_{f} \zeta}{F} \frac{Q_{f-t o t}}{I_{\text {cond-tot }}}
$$

The total conduction current $I_{\text {cond-tot }}$ is deduced from surface potential measurements $\Delta V$ (eq. 14). The total water injection (usually several liters $/ \mathrm{min}$ ) provides the value of $Q_{f-t o t}$ $\left[\mathrm{m}^{3} \mathrm{~s}^{-1}\right]$. The formation factor $F$ of the fault can be deduced from resistivity well-logging assuming Archie's law and knowing the fluid conductivity. The value of zeta potential has to be deduced from laboratory experiments published in the literature, possibly using figure 2. Murakami et al. (2001) deduced that the permeability of the fault was higher at the end of the water injection than at the beginning. Assumming different hypotheses for the zeta potential to -1 to $-10 \mathrm{mV}$ they deduced a permeability in the range $10^{-16}$ to $10^{-15} \mathrm{~m}^{2}$. The chemical properties of the injected water is important since it can decrease dramatically the zeta potential if species such as $\mathrm{Ca}^{2+}$ or $\mathrm{Al}^{3+}$ are present in high quantity. The advantage of this method is to be able to deduce the permeability at depth of the fault. 


\subsection{Self-potentiels related to hydraulic fracturing}

Since fluid flow can create streaming potentials, the hydraulic fracturing can induce streaming potentials as the fracture propagates, if the fracture remains fullfilled with water.

Laboratory experiments on hydraulic fracturing on granite samples showed that the streaming potential varies linearly with the injection pressure (Moore \& Glaser, 2007). However the SPC increases in an exponential trend when approaching the breakdown pressure. Since the permeability also shows an exponential increase with injection pressure, the authors concluded that the SPC is varying as $k^{1.5}$. The explanation was not an effect due to the surface conductivity, but a difference in the hydraulic tortuosity (David, 1993) and electric tortuosity (as suggested by Lorne et al. (1999b)) induced by dilatancy of microcracks.

The streaming potential induced by an advancing crack has been modeled by Cuevas et al. (2009). The authors modeled the streaming electric current density by defining a source-time function from the pressure profile in the propagating direction of the opening crack. The streaming electric current is maximum at the tip of the fracture and decays exponentially in front of the tip. The decay constant linearly increases with the propagation speed of the fracture. As the fractures progresses, the streaming potential observed at a distant point results from a superposition of delayed sources arising at the position of the advancing fluid front. The results show that the energy is focused in the vicinity of the advancing fracture's tip, however a tail can also be distinguished as the source behind the tip does not vanish instantaneously. Cuevas et al. (2009) could model the streaming electrical spike recorded by Moore \& Glaser (2007) during hydraulic fracturing by modeling the propagation of two cracks and adjusting the propagation velocity, the direction of propagation and the initial fracture volume. The authors concluded that direct information of the hydraulic fracture propagation can be provided by measuring the electrical field at distant.

Hydraulic stimulation is often used to stimulate fluid flow in geothermal reservoirs. Surface electrical potentials were measured when water was injected (during about 7 days) in granite at $5 \mathrm{~km}$ depth at the Soultz Hot Dry Rock site (France) (Marquis et al., 2002). An anomalous potential of about $5 \mathrm{mV}$ was interpreted as an electrokinetic effect a depth and measured at the surface because of the conductive well casing. The question of the exact origin between electrokinetic and electrochemical (Maineult, Bernabé \& Ackerer, 2006; Maineult, Jouniaux \& Bernabé, 2006) effects was raised by Darnet et al. (2004). Finally it has been shown that whatever the injection rate was, the electrochemical contribution was almost negligeable (Maineult, Darnet \& Marquis, 2006): the SP anomaly was mainly related to the temperature contrast between the in-situ brine and the injected fresh water only at the earliest stage of injection, and was essentially related to water-flows afterwards. Further investigations showed that a slow SP decay is observed after shut-in : its was interpreted as related to large fluid-flow persisting after the end of stimulation and correlated to the microseismic activity (Darnet et al., 2006). The fluid flow was not detected on hydraulic data because it took place in a zone hydraulically disconnected from the openhole. The authors concluded that the SP observations could monitor the fluid flow at the reservoir scale and revealed that the fluid flow plays a major role in the mechanical response of the reservoir to hydraulic stimulation. Another field experiment was performed with periodic pumping tests (injection/production) in a borehole penetrating a sandy aquifer (Maineult et al., 2008). The attenuation of SP amplitude with distance was roughly similar to the pressure attenuation. Therefore the authors proposed that hydraulic diffusivity could be inferred from SP observations. Moreover the comparaison between surface and borehole 
measurements suggested that nonlinear phenomena are present, probably related to the saturation and desaturation processes occuring in the vadose zone (Maineult et al., 2008).

\section{Seismo-electromagnetic conversions to detect hydraulic property contrasts}

\subsection{Theoretical background}

The electrokinetic effect can also be induced by seismic wave propagation, which leads to a relative motion between the fluid and the rock matrix. In this case the electrokinetic coefficient depends on the frequency $\omega$ as the dynamic permeability $k(\omega)$ (Smeulders et al., 1992). Pride (1994) developed the theory for the coupled electromagnetics and acoustics of porous media. The transport relations [(Pride, 1994) equations (250) and (251)] are:

$$
\begin{gathered}
\mathbf{J}_{\mathbf{e}}=\sigma(\omega) \mathbf{E}+\mathcal{L}_{e k}(\omega)\left(-\nabla p+\omega^{2} \rho_{f} \mathbf{u}_{\mathbf{s}}\right) \\
-i \omega \mathbf{J}_{\mathbf{f}}=\mathcal{L}_{e k}(\omega) \mathbf{E}+\frac{k(\omega)}{\eta}\left(-\nabla p+\omega^{2} \rho_{f} \mathbf{u}_{\mathbf{s}}\right)
\end{gathered}
$$

The electrical fields and mechanical forces which induce the electric current density $\mathbf{J}_{\mathbf{e}}$ and the fluid flow $\mathbf{J}_{\mathbf{f}}$ are, respectively, $\mathbf{E}$ and $\left(-\nabla p+i \omega^{2} \rho_{f} \mathbf{u}_{\mathbf{s}}\right)$, where $p$ is the pore-fluid pressure, $u_{s}$ is the solid displacement, $\mathbf{E}$ is the electric field, $\rho_{f}$ is the pore-fluid density, and $\omega$ is the angular frequency. The electrokinetic coupling $\mathcal{L}_{e k}(\omega)$ is now complex and frequency-dependent and describes the coupling between the seismic and electromagnetic fields (Pride, 1994; Reppert et al., 2001):

$$
\mathcal{L}_{e k}(\omega)=\mathcal{L}_{e k}\left[1-i \frac{\omega}{\omega_{c}} \frac{m}{4}\left(1-2 \frac{d}{\Lambda}\right)^{2}\left(1-i^{3 / 2} d \sqrt{\frac{\omega \rho_{f}}{\eta}}\right)^{2}\right]^{-\frac{1}{2}}
$$

where $m$ and $\Lambda$ are geometrical parameters of the pores ( $\Lambda$ is defined in Johnson et al. (1987) and $m$ is in the range $4-8), d$ the Debye length. The transition frequency $\omega_{c}$ defined in the Biot's theory separates the viscous and inertial flow domains and depends on the permeability $k_{0}$. The frequency-dependence of the streaming potential coefficient has been studied (Chandler, 1981; Cooke, 1955; Groves \& Sears, 1975; Packard, 1953; Reppert et al., 2001; Schoemaker et al., 2007; 2008; Sears \& Groves, 1978) mainly on synthetic samples. Both models (Gao \& Hu, 2010; Garambois \& Dietrich, 2001; 2002; Haartsen et al., 1998; Haartsen \& Pride, 1997; Pain et al., 2005; Schakel \& Smeulders, 2010) and laboratory experiments (Block \& Harris, 2006; Bordes et al., 2006; 2008; Chen \& Mu, 2005; Zhu et al., 1999) have been developed on these seismoelectromagnetic conversions.

Note that assuming the Helmholtz-Smoluchowski equation for the streaming potential coefficient leads to the electrokinetic coupling inversely dependent on the formation factor $F$ as:

$$
\mathcal{L}_{e k}=\frac{\epsilon_{f} \zeta}{\eta_{f} F}
$$

The formation factor is inversely related to the permeability and proportionnal to the hydraulic radius $F=C R^{2} / k_{0}$ (Paterson, 1983). Since the permeability can vary of about fifteen orders of magnitude, whereas this is not the case of the hydraulic radius, the static electrokinetic coupling $\mathcal{L}_{e k}$ will increase with increasing permeability. 


\subsection{Detection of permeability contrasts}

Two kinds of mechanical to electromagnetic conversions exist: 1) The electrokinetic signal which travels with the acoustic wave; 2) The interfacial conversion occuring at contrasts of physical properties such as permeability.

The first kind of conversion has been used to show that a reliable permeability log can be derived from electrokinetic measurements (Singer et al., 2005), using an acoustic source within a borehole (Fig. 7). Singer et al. (2005) showed by a finite element model and by laboratory experiments that the normalized coefficient defined by the electric field divided by the pressure depends $\left[\mathrm{V} \mathrm{Pa}^{-1} \mathrm{~m}^{-1}\right]$ on the permeability. This coefficient is coherent with the electrokinetic coefficient $\mathcal{L}_{e k}$ (eq. 19) per unit of conductance [S] and then should increase with increasing permeability. At low permeability the oscillating source will induce a larger solid displacement because the fluid is not easily displaced. However the relative movement between solid and fluid is limited, leading to a decrease of the electric field even if pressure increases, so that this normalized coefficient is decreased. The investigated depth of such a permeability is of the order of centimeters. The source was a short steel tube near the top of the borehole and hit on top with a hammer. The main wave propagation is a Stoneley wave which induces the electric field. The logging tool is moved step-by-step within the borehole (Fig. 7). This model showed that the normalized coefficient could detect a $0.5 \mathrm{~m}$-thick bed of permeability $10^{-13} \mathrm{~m}^{2}$ within a formation of permeability $10^{-15} \mathrm{~m}^{2}$. The measured amplitude of the normalized coefficient on sandstones is in the range $1.6 \times 10^{-7}$ to $2.5 \times 10^{-6}\left[\mathrm{~V} \mathrm{~Pa}^{-1} \mathrm{~m}^{-1}\right.$ ] increasing with increasing permeabilities from $6.210^{-15} \mathrm{~m}^{2}$ to $2.2 \times 10^{-12} \mathrm{~m}^{2}$.

The second kind of conversion can be used to detect contrasts in permeability in the crust. The seismic source induces a seismic wave propagation downward up to the interface (Fig. 8). Because of the difference in the physical properties there is a charge inbalance that causes a charge separation on both sides of the interface. This acts as en electric dipole which emits an electromagnetic wave that travels with the speed of the light in the medium and that can be detected at the surface (Fig. 9). The velocity of the seismic wave propagation is deduced by surface measurements of the soil velocity. Then the depth of the interface can be deduced by picking the time arrival of the electromagnetic wave. Usually the seismoelectric signals show low amplitude from $100 \mu \mathrm{V}$ to $\mathrm{mV}$. Then signal processing needs filtering techniques such as Butler \& Russell (1993). The advantage of this method is to detect the contrasts of permeability at depth from few meters to few hundreds of meters (Dupuis \& Butler, 2006; Dupuis et al., 2007; Dupuis et al., 2009; Haines, Guitton \& Biondi, 2007; Haines, Pride, Klemperer \& Biondi, 2007; Strahser et al., 2007; 2011; Thompson et al., 2005).

\section{Limitations of this technique}

The limitations of this technique arise from the low amplitude of the electrical signal. It needs good pre-amplifiers to be able to detect the signals. Then it needs an adapted signal processing to remove the anthropic noise, and further filtering techniques to extract the expected signal from the remaining records. The interpretation of self-potential observations may not be easy if the signals are induced not only by the electrokinetic effect, but also by a thermoelectric effect, and by an electrochemical effect. The interpretation of the seismo-electric conversion may not be easy if the contrast in the permeability is not high enough. 


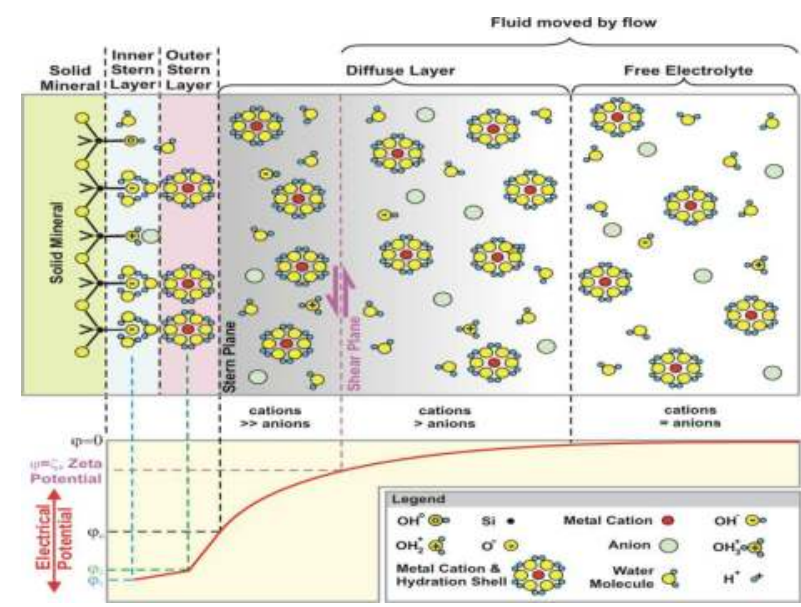

Fig. 1. Electric double layer, courtesy of P.W.J. Glover (Glover \& Jackson, 2010). The solid mineral presented is the case of silica. At $p H$ above the isoelectric point the cations are adsorbed within the Stern layer; there is an excess of cations in the diffuse layer. The zeta potential is defined at the shear plane. The fluid flow creates a streaming current which is balanced by the conduction current, leading to the streaming potential.

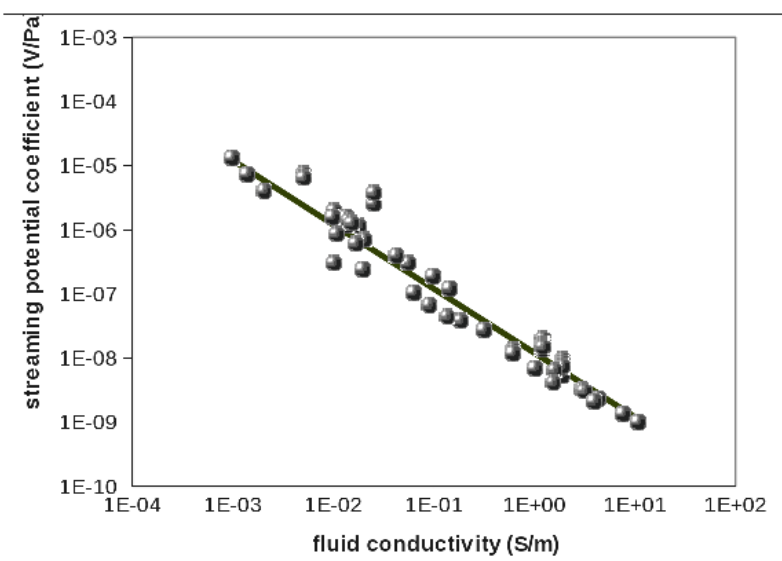

Fig. 2. Streaming potential coefficient from data collected (in absolute value) on sands and sandstones at pH 7-8 (when available) from Ahmad (1964); Guichet et al. (2006; 2003); Ishido \& Mizutani (1981); Jaafar et al. (2009); Jouniaux \& Pozzi (1997); Li et al. (1995); Lorne et al. (1999a); Pengra et al. (1999); Perrier \& Froidefond (2003). The regression (black line) leads to $C_{s 0}=-1.2 \times 10^{-8} \sigma_{f}^{-1}$. A zeta potential of $-17 \mathrm{mV}$ can be inferred from these collected data (from Allègre et al. (2010)). 


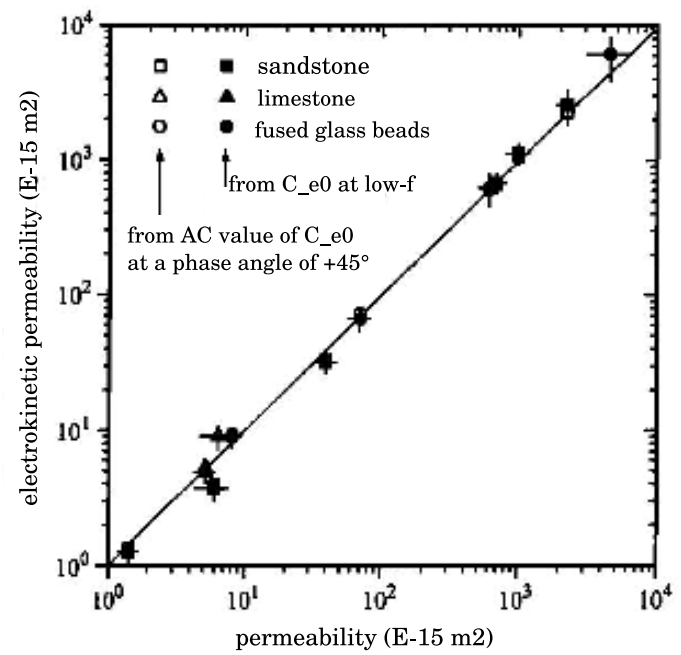

Fig. 3. Comparison between the permeability $k$ and the electrokinetic permeability $k_{e}$. The solid line is $k_{e}=k$ (modified from Pengra et al. (1999)).

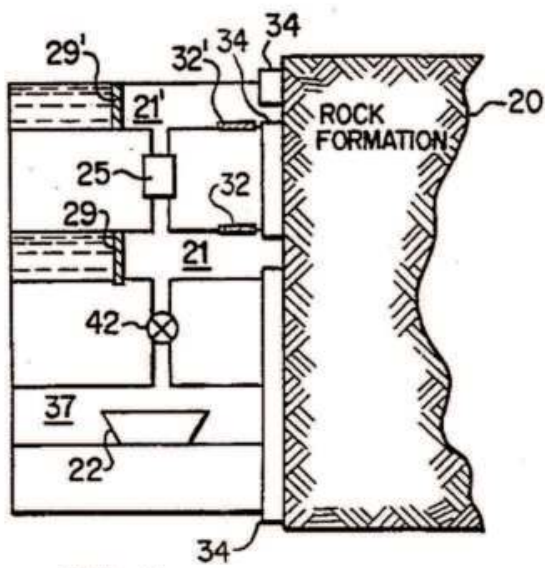

FIG. 4

Fig. 4. In-situ permeability measurement (from Wong (1995)) from streaming potential and electro-osmosis measurements using eq. 11. For the streaming potential measurement: an oscillating presure is applied by electromechanical transducer (22) to the rock formation (20) through fluid chamber (21) with valve (42) open. The pressure differential in the rock between fluid chamber (21) and (21') is measured by a pressure sensor (25) and the induced voltage difference is measured by the voltage electrodes (32) and (32'). For the electro-osmosis measurements the valve (42) is closed, the pressure difference induced when a current is passed through the rock (by current electrodes 29 and $29^{\prime}$ ) is measured by pressure sensor (25). 


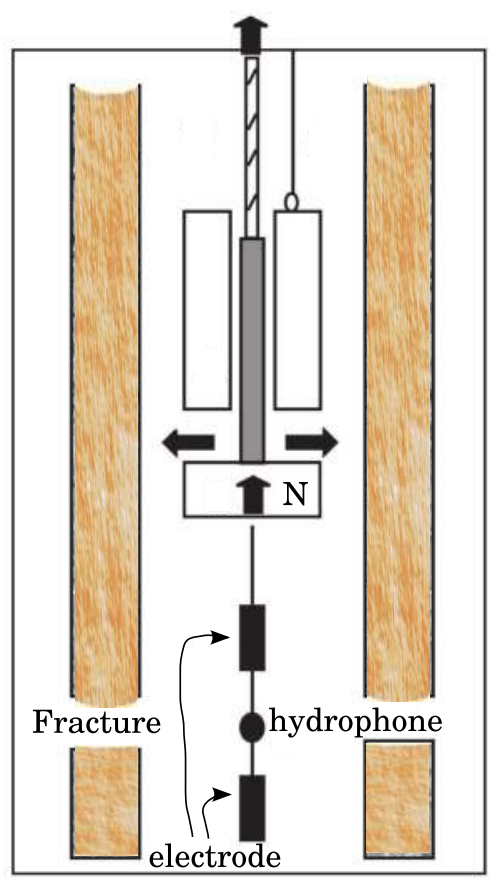

Fig. 5. Scheme of the principle of borehole electrokinetic response to detect fractures (modified from Hunt \& Worthington (2000)). The source is a nylon block (N) pulled by the rope, which induces fluid flow near the wall of the rock formation, leading to an electrokinetic effect. The electrodes are $1 \mathrm{~m}$ apart. The hydrophone is $2.5 \mathrm{~m}$ below the source. The electrode response is normalized by the peak pressure. 


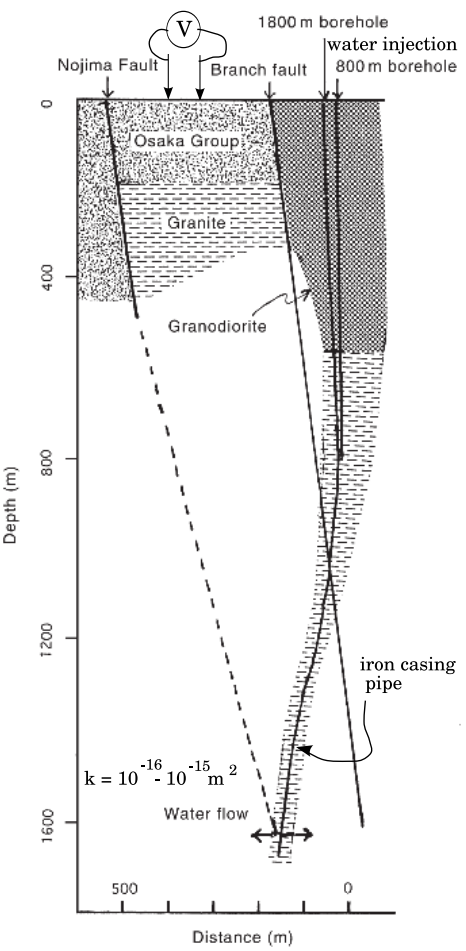

Fig. 6. Measurement of the permeability of the Nojima fault (modified from Murakami et al. (2001)). The water injection inside the borehole of $1800 \mathrm{~m}$ depth crosses the fault inducing an electrokinetic source at depth within the fault. The conduction current is conducted by the iron pipe up to the surface. The difference of potential $\mathrm{V}$ is measured by electrodes on the surface. The permeability is deduced from eq. 15 


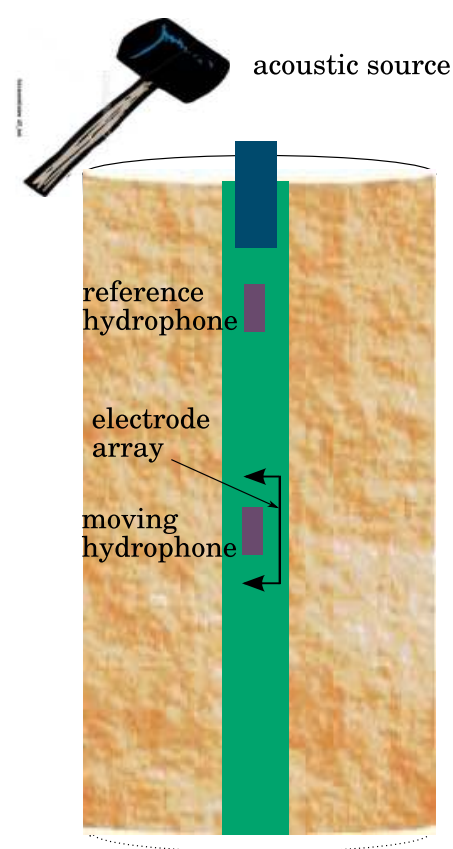

Fig. 7. Scheme of the principle of electrokinetic logging to measure the permeability (modified from Singer et al. (2005)). The acoustic source induces a Stoneley wave propagation (detected by the hydrophones) leading to an electric field (measured by the electrodes). The experiment is repeated by moving the tool downward. 


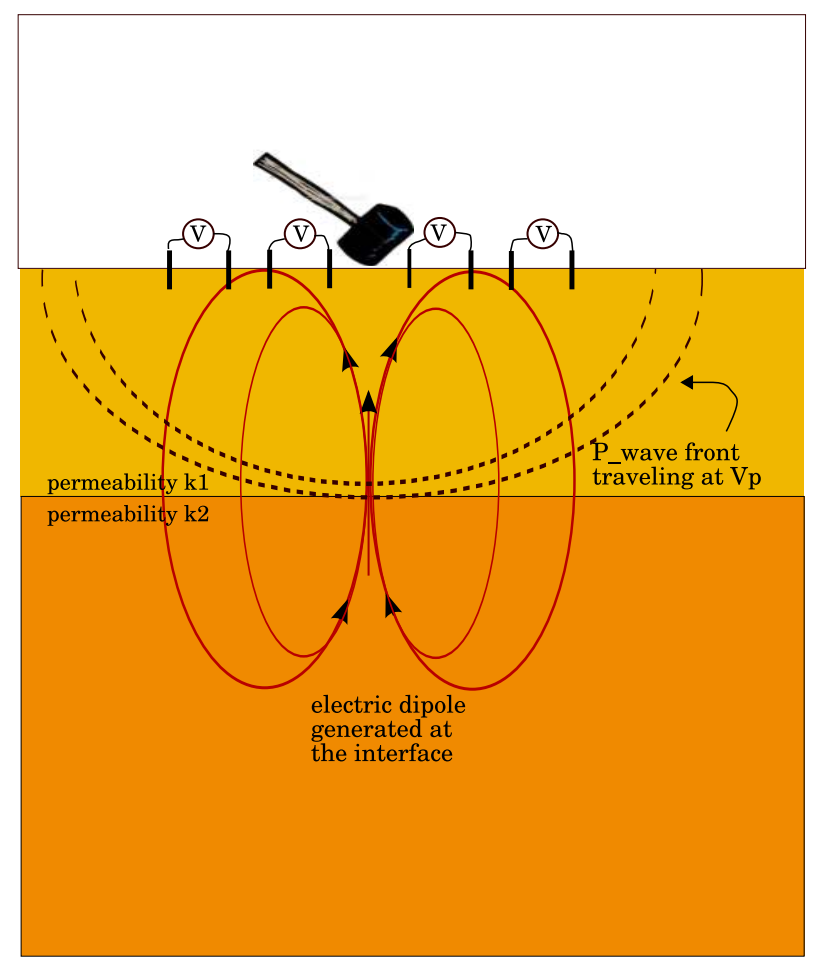

Fig. 8. The seismic waves propagates up to the interface where an electric dipole is generated because of the contrast in permeability. This electromagnetic wave can be detected at the surface by measuring the difference of the electrical potential V between electrodes. Picking the time arrival allows to know the depth of the interface. 


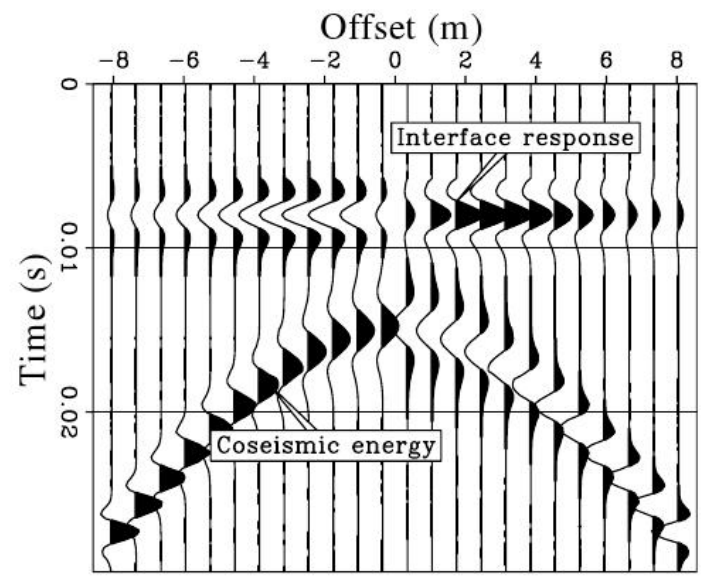

Fig. 9. Model of the seimoelectric response to a hammer strike on the surface at position zero (from Haines (2004)). The seismoelectric signal is shown as measured at the surface along a line centered on the seismic source. The interfacial signal is related to a contrast between properties of the media, such as the permeability.

\section{Conclusion}

The electrokinetic properties can be used to deduce permeability in the crust, possibly at depth, within fault, and along boreholes. Some conditions are needed to be able to use electrokinetic coupling to infer hydraulic properties. The electrical noise can prevent being able to detect small electric potentials, even using appropriate filtering techniques. When possible, the joint inversion with other observations can improve parameters such as electrical conductivity. The seismoelectric method could provide deeper investigations when using stronger seismic sources.

\section{Acknowledgements}

This work was supported by the French National Scientific Center (CNRS), by ANR-TRANSEK, and by REALISE the "Alsace Region Research Network in Environmental Sciences in Engineering" and the Alsace Region.

\section{References}

Adamson, A. W. (1976). Physical chemistry of surfaces, John Wiley and sons, New York. Ahmad, M. (1964). A laboratory study of streaming potentials, Geophys. Prospect. XII: 49-64. Allègre, V., Jouniaux, L., Lehmann, F. \& Sailhac, P. (2010). Streaming Potential dependence on water-content in fontainebleau sand, Geophys. J. Int. 182: 1248-1266.

Allègre, V., Jouniaux, L., Lehmann, F. \& Sailhac, P. (2011). Reply to the comment by A. Revil and N. Linde on: "Streaming potential dependence on water-content in fontainebleau sand" by Allègre et al., Geophys. J. Int. 186: 115-117.

Archie, G. E. (1942). The electrical resistivity $\log$ as an aid in determining some reservoir characteristics, Trans. Am. Inst. Min. Metall. Pet. Eng. (146): 54-62. 
Aubert, M. \& Atangana, Q. Y. (1996). Self-potential method in hydrogeological exploration of volcanic areas, Ground Water 34: 1010-1016.

Auriault, J. \& Strzelecki, T. (1981). On the electro-osmotic flow in saturated porous media, Int. J. Engrg. Sci. 19: 915-928.

Beddiar, K., Berthaud, Y. \& Dupas, A. (2002). Experimental verification of the onsager's reciprocal relations for electro-osmosis and electro-filtration phenomena on a saturated clay, C. R. Mécanique 330: 893-898.

Beddiar, K., Fen-Chong, T., Dupas, A., Berthaud, Y. \& Dangla, P. (2005). Role of ph in electro-osmosis: Experimental study on nacl-water saturated kaolinite, Transport in Porous media 61: 93-107.

Block, G. I. \& Harris, J. G. (2006). Conductivity dependence of seismoelectric wave phenomena in fluid-saturated sediments, J. Geophys. Res. 111: B01304.

Bordes, C., Jouniaux, L., Dietrich, M., Pozzi, J.-P. \& Garambois, S. (2006). First laboratory measurements of seismo-magnetic conversions in fluid-filled Fontainebleau sand, Geophys. Res. Lett. 33: L01302.

Bordes, C., Jouniaux, L., Garambois, S., Dietrich, M., Pozzi, J.-P. \& Gaffet, S. (2008). Evidence of the theoretically predicted seismo-magnetic conversion, Geophys. J. Int. 174: 489-504.

Butler, K. E. \& Russell, R. D. (1993). Substraction of powerline harmonics from geophysical records, Geophysics 58: 898-903.

Chandler, R. (1981). Transient streaming potential measurements on fluid-saturated porous structures: An experimental verification of Biot's slow wave in the quasi-static limit, J. Acoust. Soc. Am. 70: 116-121.

Chen, B. \& Mu, Y. (2005). Experimental studies of seismoelectric effects in fluid-saturated porous media, J. Geophys. Eng. 2: 222-230.

Cooke, C. E. (1955). Study of electrokinetic effects using sinusoidal pressure and voltage, J. Chem. Phys. (23): 2299-2303.

Cuevas, N., Moore, J. \& Glaser, S. (2009). Electrokinetic coupling in hydraulic fracture propagation, SEG Technical Program Expanded Abstracts 28: 1721-1725.

Darnet, M., G.Marquis \& Sailhac, P. (2006). Hydraulic stimulation of geothermal reservoirs:fluid flow, electric potential and microseismicity relationships, Geophys. J. Int. 166: 438-444.

Darnet, M., Maineult, A. \& Marquis, G. (2004). On the origins of self-potential (sp) anomalies induced by water injections into geothermal reservoirs, Geophys. Res. Lett. 31: L19609.

Darnet, M. \& Marquis, G. (2004). Modelling streaming potential (sp) signals induced by water movement in the vadose zone, J. Hydrol. 285: 114-124.

David, C. (1993). Geometry of flow paths for fluid transport in rocks, J. Geophys. Res. 98: $12267-12278$.

Davis, J. A., James, R. O. \& Leckie, J. (1978). Surface ionization and complexation at the oxide/water interface, J. Colloid Interface Sci. 63: 480-499.

Davis, J. \& Kent, D. (1990). Surface complexation modeling in aqueous geochemistry, in Mineral Water Interface Geochemistry, M.F. Hochella and A.F. White, Mineralogical Society of America.

Doussan, C. \& Ruy, S. (2009). Prediction of unsaturated soil hydraulic conductivity with electrical conductivity, Water Resources Res. 45: W10408.

Dukhin, S. S. \& Derjaguin, B. V. (1974). Surface and Colloid Science, edited by E. Matijevic, John Wiley and sons, New York. 
Dupuis, J. C. \& Butler, K. E. (2006). Vertical seismoelectric profiling in a borehole penetrating glaciofluvial sediments, Geophys. Res. Lett. 33.

Dupuis, J. C., Butler, K. E. \& Kepic, A. W. (2007). Seismoelectric imaging of the vadose zone of a sand aquifer, Geophysics 72: A81-A85.

Dupuis, J. C., Butler, K. E., Kepic, A. W. \& Harris, B. D. (2009). Anatomy of a seismoelectric conversion: Measurements and conceptual modeling in boreholes penetrating a sandy aquifer, J. Geophys. Res. Solid Earth 114(B13): B10306.

El-kaliouby, H. \& Al-Garni, M. (2009). Inversion of self-potential anomalies caused by 2d inclined sheets using neural networks, J. Geophys. Eng. 6: 29-34.

Fagerlund, F. \& Heison, G. (2003). Detecting subsurface grounwater flow in fractured rock using self-potential (sp) methods, Environmental Geology 43: 782-794.

Fernandez-Martinez, J., Garcia-Gonzalo, E. \& Naudet, V. (2010). Particle swarm optimization applied to solving and appraising the streaming potential inverse problem, Geophysics 75: WA3-WA15.

Finizola, A., Sortino, F., L/'enat, J.-F. \& Aubert, M. (2003). The summit hydrothermal system of stromboli, new insights from self-potential temperature, $\mathrm{c} 02$ and fumarolic fluid measurements, with structural and monitoring implications, Bulletin of Volcanology (65): 486-504.

Gao, Y. \& Hu, H. (2010). Seismoelectromagnetic waves radiated by a double couple source in a saturated porous medium, Geophys. J. Int. 181: 873-896.

Garambois, S. \& Dietrich, M. (2001). Seismoelectric wave conversions in porous media: Field measurements and transfer function analysis, Geophysics 66: 1417-1430.

Garambois, S. \& Dietrich, M. (2002). Full waveform numerical simulations of seismoelectromagnetic wave conversions in fluid-saturated stratified porous media, J. Geophys. Res. 107(B7): ESE 5-1.

Gibert, D. \& Pessel, M. (2001). Identification of sources of potential fields with the continuous wavelet transform: Application to self-potential profiles, Geophys. Res. Lett. 28: 1863-1866.

Gibert, D. \& Sailhac, P. (2008). Comment on: Self-potential signals associated with preferential grounwater flow pathways in sinkholes, by A. Jardani J.P dupont A. Revil, J. Geophys. Res. 113: B03210.

Glover, P. \& Jackson, M. (2010). Borehole electrokinetics, The Leading Edge pp. 724-728.

Glover, P. W. J. \& Walker, E. (2009). Grain-size to effective pore-size transformation derived from electrokinetic theory, Geophysics 74: E17-E29.

Glover, P. W. J., Zadjali, I. I. \& Frew, K. A. (2006). Permeability prediction from MICP and NMR data using an electrokinetic approach, Geophysics 71: F49-F60.

Groves, J. \& Sears, A. (1975). Alternating streaming current measurements, J. Colloid Interface Sci. 53: 83-89.

Guichet, X., Jouniaux, L. \& Catel, N. (2006). Modification of streaming potential by precipitation of calcite in a sand-water system: laboratory measurements in the $\mathrm{pH}$ range from 4 to 12, Geophys. J. Int. 166: 445-460.

Guichet, X., Jouniaux, L. \& Pozzi, J.-P. (2003). Streaming potential of a sand column in partial saturation conditions, J. Geophys. Res. 108(B3): 2141.

Haartsen, M. W., Dong, W. \& Toksöz, M. N. (1998). Dynamic streaming currents from seismic point sources in homogeneous poroelastic media, Geophys. J. Int. 132: 256-274.

Haartsen, M. W. \& Pride, S. (1997). Electroseismic waves from point sources in layered media, J. Geophys. Res. 102: 24,745-24,769. 
Haines, S. (2004). Seismoelectric imaging of shallow targets, PhD dissertation (Stanford University).

Haines, S. S., Guitton, A. \& Biondi, B. (2007). Seismoelectric data processing for surface surveys of shallow targets, Geophysics 72: G1-G8.

Haines, S. S., Pride, S. R., Klemperer, S. L. \& Biondi, B. (2007). Seismoelectric imaging of shallow targets, Geophysics 72: G9-G20.

Henry, P., Jouniaux, L., Screaton, E. J., S.Hunze \& Saffer, D. M. (2003). Anisotropy of electrical conductivity record of initial strain at the toe of the Nankai accretionary wedge, $J$. Geophys. Res. 108: 2407.

Hunt, C. W. \& Worthington, M. H. (2000). Borehole elektrokinetic responses in fracture dominated hydraulically conductive zones, Geophys. Res. Lett. 27(9): 1315-1318.

Hunter, R. (1981). Zeta Potential in Colloid Science: Principles and Applications, Academic., New York.

Ishido, T. \& Mizutani, H. (1981). Experimental and theoretical basis of electrokinetic phenomena in rock water systems and its applications to geophysics, J. Geophys. Res. 86: 1763-1775.

Ishido, T., Mizutani, H. \& Baba, K. (1983). Streaming potential observations, using geothermal wells and in situ electrokinetic coupling coefficients under high temperature, Tectonophysics 91: 89-104.

Ishido, T. \& Pritchett, J. (1999). Numerical simulation of electrokinetic potentials associated with subsurface fluid flow, J. Geophys. Res. 104(B7): 15247-15259.

Jaafar, M. Z., Vinogradov, J. \& Jackson, M. D. (2009). Measurement of streaming potential coupling coefficient in sandstones saturated with high salinity nacl brine, Geophys. Res. Lett. 36.

Jackson, M. D. (2010). Multiphase electrokinetic coupling: Insights into the impact of fluid and charge distribution at the pore scale from a bundle of capillary tubes model, $J$. Geophys. Res. 115: B07206.

Johnson, D. L., Koplik, J. \& Dashen, R. (1987). Theory of dynamic permeability in fluid saturated porous media, J. Fluid. Mech. 176: 379-402.

Jouniaux, L., Bernard, M.-L., Zamora, M. \& Pozzi, J.-P. (2000). Streaming potential in volcanic rocks from Mount Peleé, J. Geophys. Res. 105: 8391-8401.

Jouniaux, L., Lallemant, S. \& Pozzi, J. (1994). Changes in the permeability, streaming potential and resistivity of a claystone from the Nankai prism under stress, Geophys. Res. Lett. 21: 149-152.

Jouniaux, L., Maineult, A., Naudet, V., Pessel, M. \& Sailhac, P. (2009). Review of self-potential methods in hydrogeophysics, C.R. Geosci. 341: 928-936.

Jouniaux, L. \& Pozzi, J.-P. (1995a). Permeability dependence of streaming potential in rocks for various fluid conductivity, Geophys. Res. Lett. 22: 485-488.

Jouniaux, L. \& Pozzi, J.-P. (1995b). Streaming potential and permeability of saturated sandstones under triaxial stress: consequences for electrotelluric anomalies prior to earthquakes, J. Geophys. Res. 100: 10,197-10,209.

Jouniaux, L. \& Pozzi, J.-P. (1997). Laboratory measurements anomalous 0.1-0.5 Hz streaming potential under geochemical changes: Implications for electrotelluric precursors to earthquakes, J. Geophys. Res. 102: 15,335-15,343.

Jouniaux, L., Pozzi, J.-P., Berthier, J. \& Massé, P. (1999). Detection of fluid flow variations at the Nankai trough by electric and magnetic measurements in boreholes or at the seafloor, J. Geophys. Res. 104: 29293-29309. 
Jouniaux, L., Zamora, M. \& Reuschlé, T. (2006). Electrical conductivity evolution of non-saturated carbonate rocks during deformation up to failure, Geophys. J. Int. 167: 1017-1026.

Lesmes, D. P. \& Friedman, S. P. (2005). Relationships between the electrical and hydrogeological properties of rocks and soils, Hydrogeophysics, Springer, Dordrecht, The Netherlands, chapter 4, pp. 87-128.

Li, S., Pengra, D. \& Wong, P. (1995). Onsager's reciprocal relation and the hydraulic permeability of porous media, Physical Review E 51(6): 5748-5751.

Lorne, B., Perrier, F. \& Avouac, J.-P. (1999a). Streaming potential measurements. 1. properties of the electrical double layer from crushed rock samples, J. Geophys. Res. 104(B8): 17,857-17,877.

Lorne, B., Perrier, F. \& Avouac, J.-P. (1999b). Streaming potential measurements. 2. relationship between electrical and hydraulic flow patterns from rocks samples during deformations, J. Geophys. Res. 104(B8): 17,879-17,896.

Maineult, A., Bernabé, Y. \& Ackerer, P. (2006). Detection of advected, recating redox fronts from self-potential measurements, J. Contaminant Hydrology (86): 32-52.

Maineult, A., Darnet, M. \& Marquis, G. (2006). Correction to on the origins of self-potential (sp) anomalies induced by water injections into geothermal reservoirs, Geophys. Res. Lett. (33): L20319.

Maineult, A., Jouniaux, L. \& Bernabé, Y. (2006). Influence of the mineralogical composition on the self-potential response to advection of kcl concentration fronts through sand, Geophys. Res. Lett. (33): L24311.

Maineult, A., Strobach, E. \& Renner, J. (2008). Self-potential signals induced by periodic pumping, J. Geophys. Res. 113: B01203.

Marquis, G., Darnet, M., Sailhac, P., Singh, A. K. \& Gérard, A. (2002). Surface electric variations induced by deep hydraulic stimulation: an example from the soultz hdr site, Geophys. Res. Lett. 29.

Miller, D. (1960). Thermodynamics of irreversible processes, the experimental verification of onsager reciprocal relations, Chem. Rev. 60(1): 15-37.

Minsley, B., Sogade, J. \& Morgan, F. (2007). Three-dimensional modelling source inversion of self-potential data, J. Geophys. Res. 112: B02202.

Moore, J. \& Glaser, S. (2007). Self-potential observations during hydraulic fracturing, J. Geophys. Res. 112: B02204.

Moreau, F., Gibert, D. \& Saracco, G. (1996). Filtering non-stationnary geophysical data with orthogonal wavelets, Geophys. Res. Lett. 23(4): 407-410.

Murakami, H., Hashimoto, T., N.Oshiman, Yamaguchi, S., Honkuba, Y. \& Sumitomo, N. (2001). Electrokinetic phenomena associated with a water injection experiment at the nojima fault on awaji island, japan, The Island Arc 10: 244-251.

Naudet, V., Fernandez-Martinez, J., Garcia-Gonzalo, E. \& Fernandez-Alvarez, J. (2008). Estimation of water table from self-potential data using particle swarm optimization (pso), SEG Expanded Abstracts 27: 1203.

Onsager, L. (1931). Reciprocal relations in irreversible processes:i, Phys. Rev. 37: 405-426.

Overbeek, J. T. G. (1952). Electrochemistry of the double layer, Colloid Science, Irreversible Systems, edited by H. R. Kruyt, Elsevier 1: 115-193.

Packard, R. G. (1953). Streaming potentials across capillaries for sinusoidal pressure, J. Chem. Phys 1(21): 303-307. 
Pain, C., Saunders, J. H., Worthington, M. H., Singer, J. M., Stuart-Bruges, C. W., Mason, G. \& Goddard., A. (2005). A mixed finite-element method for solving the poroelastic Biot equations with electrokinetic coupling, Geophys. J. Int. 160: 592-608.

Paterson, M. (1983). The equivalent channel model for permeability and resistivity in fluid-saturated rock- a re-appraisal, Mechanics of Materials 2: 345-352.

Pengra, D. B., Li, S. X. \& Wong, P.-Z. (1999). Determination of rock properties by low frequency ac electrokinetics, J. Geophys. Res. 104(B12): 29.485-29.508.

Perrier, F. E., Petiau, G., Clerc, G., Bogorodsky, V., Erkul, E., Jouniaux, L., Lesmes, D., Magnae, J., Meunier, J.-M., Morgan, D., Nascimento, D., Oettinger, G., Schwartz, G., Toh, H., Valiant, M.-J., Vozoff, K. \& Yazici-Cakin, O. (1997). A one-year systematic study of electrodes for long period measurements of the electric field in geophysical environments, J. Geomag. Geoelectr 49: 1677-1696.

Perrier, F. \& Froidefond, T. (2003). Electrical conductivity and streaming potential coefficient in a moderately alkaline lava series, Earth and Planetary Science Letters 210: 351-363.

Perrier, F. \& Morat, P. (2000). Characterization of electrical daily variations induced by capillary flow in the non-saturated zone, Pure Appl. Geophys. 157: 785-810.

Perrier, F., Trique, M., Lorne, B., Avouac, J.-P., Hautot, S. \& Tarits, P. (1998). Electric potential variations associated with lake variations, Geophys. Res. Lett. 25: 1955-1958.

Petiau, G. (2000). Second generation of lead-lead chloride electrodes for geophysical applications, Pure Appl. Geophys. 3: 357-382.

Petiau, G. \& Dupis, A. (1980). Noise, temperature coefficient and long time stability of electrodes for telluric observations, Geophys. Prospect. 28(5): 792-804.

Pezard, P., Gautier, S., Borgne, T. L., Legros, B. \& Deltombe, J.-L. (2009). Muset: A multiparameter and high precision sensor for downhole spontaneous electrical potential measurements, Comptes Rendus - Geoscience 341: 957-964.

Pinettes, P., Bernard, P., Cornet, F., Hovhannissian, G., Jouniaux, L., Pozzi, J.-P. \& Barthés, V. (2002). On the difficulty of detecting streaming potentials generated at depth, Pure Appl. Geophys. 159: 2629-2657.

Pride, S. (1994). Governing equations for the coupled electromagnetics and acoustics of porous media, Phys. Rev. B: Condens. Matter 50: 15678-15695.

Pride, S. \& Morgan, F. D. (1991). Electrokinetic dissipation induced by seismic waves, Geophysics 56(7): 914-925.

Reppert, P. M., Morgan, F. D., Lesmes, D. P. \& Jouniaux, L. (2001). Frequency-dependent streaming potentials, J. Colloid Interface Sci. (234): 194-203.

Sailhac, P., Darnet, M. \& Marquis, G. (2004). Electrical streaming potential measured at the ground surface: forward modeling and inversion issues for monitoring infiltration and characterizing the vadose zone, Vadose Zone J. (3): 1200-1206.

Saracco, G., Labazuy, P. \& Moreau, F. (2004). Localization of self-potential sources in volcano-electric effect with complex continuous wavelet transform and electrical tomography methods for an active volcano, Geophys. Res. Lett. (31): L12610.

Saunders, J. H., Jackson, M. D. \& Pain, C. C. (2008). Fluid flow monitoring in oilfields using downhole measurements of electrokinetic potential, Geophysics 73: E165-E180.

Schakel, M. \& Smeulders, D. (2010). Seismoelectric reflection and transmission at a fluid/porous-medium interface, J. Acoust. Soc. Am. 127: 13-21.

Schoemaker, F., Smeulders, D. \& Slob, E. (2007). Simultaneous determination of dynamic permeability and streaming potential, SEG expanded abstracts 26: 1555-1559. 
Schoemaker, F., Smeulders, D. \& Slob, E. (2008). Electrokinetic effect: Theory and measurement, SEG Technical Program Expanded Abstracts pp. 1645-1649.

Schön, J. (1996). Physical properties of rocks - fundamentals and principles of petrophysics, Vol. 18, Elsevier Science Ltd., Handbook of Geophysical Exploration, Seismic exploration.

Sears, A. \& Groves, J. (1978). The use of oscillating laminar flow streaming potential measurements to determine the zeta potential of a capillary surface, J. Colloid Interface Sci. 65: 479-482.

Sheffer, M. \& Oldenburg, D. (2007). Three-dimensional modelling of streaming potential, Geophys. J. Int. 169: 839-848.

Singer, J., J.Saunders, Holloway, L., Stoll, J., C.Pain, Stuart-Bruges, W. \& Mason, G. (2005). Electrokinetic logging has the potential to measure the permeability, Society of Petrophysicists and Well Log Analysts, 46th Annual Logging Symposium .

Smeulders, D., Eggels, R. \& van Dongen, M. (1992). Dynamic permeability: reformulation of theory and new experimental and numerical data, J. Flui. Mech. 245: 211-227.

Sposito, G. (1989). The chemistry of soils, Oxford University, Oxford.

Strahser, M. H. P., Rabbel, W. \& Schildknecht, F. (2007). Polarisation and slowness of seismoelectric signals: a case study, Near Surface Geophysics 5: 97-114.

Strahser, M., Jouniaux, L., Sailhac, P., Matthey, P.-D. \& Zillmer, M. (2011). Dependence of seismoelectric amplitudes on water-content, Geophys. J. Int. in press.

Thompson, A., Hornbostel, S., Burns, J., Murray, T., Raschke, R., Wride, J., McCammon, P., Sumner, J., Haake, G., Bixby, M., Ross, W., White, B., Zhou, M. \& Peczak, P. (2005). Field tests of electroseismic hydrocarbon detection, SEG Technical Program Expanded Abstracts .

Vinogradov, J., Jaafar, M. \& Jackson, M. D. (2010). Measurement of streaming potential coupling coefficient in sandstones saturated with natural and artificial brines at high salinity, J. Geophys. Res. 115: B12204.

Wong, P. (1995). Determination of permeability of porous media by streaming potential and electro-osmotic coefficients, United States Patent Number 5,417,104.

Zhu, Z., Haartsen, M. W. \& Toksöz, M. N. (1999). Experimental studies of electrokinetic conversions in fluid-saturated borehole models, Geophysics 64: 1349-1356. 


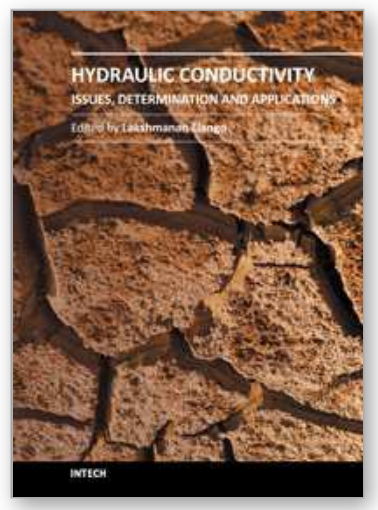

\author{
Hydraulic Conductivity - Issues, Determination and Applications \\ Edited by Prof. Lakshmanan Elango
}

ISBN 978-953-307-288-3

Hard cover, 434 pages

Publisher InTech

Published online 23, November, 2011

Published in print edition November, 2011

There are several books on broad aspects of hydrogeology, groundwater hydrology and geohydrology, which do not discuss in detail on the intrigues of hydraulic conductivity elaborately. However, this book on Hydraulic Conductivity presents comprehensive reviews of new measurements and numerical techniques for estimating hydraulic conductivity. This is achieved by the chapters written by various experts in this field of research into a number of clustered themes covering different aspects of hydraulic conductivity. The sections in the book are: Hydraulic conductivity and its importance, Hydraulic conductivity and plant systems, Determination by mathematical and laboratory methods, Determination by field techniques and Modelling and hydraulic conductivity. Each of these sections of the book includes chapters highlighting the salient aspects and most of these chapters explain the facts with the help of some case studies. Thus this book has a good mix of chapters dealing with various and vital aspects of hydraulic conductivity from various authors of different countries.

\title{
How to reference
}

In order to correctly reference this scholarly work, feel free to copy and paste the following:

Laurence Jouniaux (2011). Electrokinetic Techniques for the Determination of Hydraulic Conductivity, Hydraulic Conductivity - Issues, Determination and Applications, Prof. Lakshmanan Elango (Ed.), ISBN: 978953-307-288-3, InTech, Available from: http://www.intechopen.com/books/hydraulic-conductivity-issuesdetermination-and-applications/electrokinetic-techniques-for-the-determination-of-hydraulic-conductivity

\section{INTECH}

open science | open minds

\section{InTech Europe}

University Campus STeP Ri

Slavka Krautzeka 83/A

51000 Rijeka, Croatia

Phone: +385 (51) 770447

Fax: +385 (51) 686166

www.intechopen.com

\section{InTech China}

Unit 405, Office Block, Hotel Equatorial Shanghai

No.65, Yan An Road (West), Shanghai, 200040, China

中国上海市延安西路65号上海国际贵都大饭店办公楼 405 单元

Phone: +86-21-62489820

Fax: $+86-21-62489821$ 
(C) 2011 The Author(s). Licensee IntechOpen. This is an open access article distributed under the terms of the Creative Commons Attribution 3.0 License, which permits unrestricted use, distribution, and reproduction in any medium, provided the original work is properly cited. 